\title{
Plasma Protein Adsorption to Anion Substituted Poly(vinyl alcohol) Membranes
}

\author{
Kyu Eun Ryu, Hyangshuk Rhim, ${ }^{1}$ Chong Won Park, and Heung Jae Chun* \\ Department of Biomedical Sciences, and ${ }^{1}$ Division of Hematology, Department of Internal Medicine, \\ College of Medicine, Catholic University, Seoul 137-701, Korea \\ Seung Hwa Hong \\ Blood Products Division, Biologics Evaluation Department, Korea Food and Drug Administration, Seoul 122-704, Korea
}

\author{
Jae Jin Kim
}

Biomaterials Research Center, Korea Institute of Science and Technology, Seoul 130-650, Korea

Young Moo Lee

School of Chemical Engineering, College of Engineering, Hanyang University, Seoul 133-791, Korea

Received June 12, 2003; Revised Nov. 11, 2003

\begin{abstract}
Anion-substituted poly(vinyl alcohol) (PVA) membranes, carboxymethylated PVA (C-PVA), and sulfonated PVA (S-PVA) were prepared and the effects of these substitutions on the plasma protein adsorption were studied by one- and two-dimensional gel electrophoresis and immunoblotting. When Cuprophane was used as a negative control, the amount of total proteins bound to samples decreased in the order Cuprophane $>$ PVA $>$ C-PVA $>$ S-PVA, which we attribute to the effects of the surface characteristics of the samples, such as their surface tensions and electrostatic properties, on the adsorption of proteins to the surfaces of the materials. The results revealed that albumin was the most abundant protein in all the samples. The proportion of adsorbed fibrinogen to S-PVA exceeded those of PVA and C-PVA, whereas S-PVA exhibited the lowest IgG adsorption affinity among the samples we studied.
\end{abstract}

Keywords: carboxymethylated poly(vinyl alcohol), sulfonated poly(vinyl alcohol), hemodialysis membrane, plasma protein adsorption.

\section{Introduction}

In the science of biomaterials, adsorption of proteins on the surface of materials is one of major concerns, because the protein deposits exert strong influence on the subsequent cellular interactions with surfaces. ${ }^{1}$ Properties of the surfaces of materials, together with those of individual proteins, determine the organization of the adsorbed protein layer, and the nature of this layer, in turn, determines the cellular response to the adsorbed surfaces. ${ }^{2}$ Because the cellular responses largely determine the degree of biocompatibility of the material, the properties of proteins and their behavior at interfaces should be understood. ${ }^{1,2}$ In hemodialysis, indeed, the interaction between plasma and membrane surface is very important, because exposure of blood to the membrane surface leads to the deposition of a heterogeneous

*e-mail: chunhj@catholic.ac.kr

1598-5032/12/451-07 @2003 Polymer Society of Korea protein film that precedes subsequent adverse effects of hemodialysis, such as activation of cells, coagulation, and complement activation.,

In previous works, as synthetic analogues of heparin, crosslinked poly(vinyl alcohols), which were prepared by replacing hydroxyl groups of PVA with carboxymethyl and sulfonyl groups, were found to possess significant anticoagulating properties. ${ }^{5,6}$ In addition, the crosslinked PVA copolymers showed mechanical properties and permeability suitable for use as blood-contacting membranes by controlling the cross-linking conditions..$^{6-8}$ Nonetheless, changes in the proteins bound to the modified surface should also be elucidated, because this is a fundamental subject that must be understood to fully appreciate the protein behavior as well as subsequent cellular interactions with the surfaces.

The present work describes the effects of substituting hydroxyl groups in PVA with carboxyl and sulfonyl groups on the plasma protein adsorption behavior. 


\section{Experimental}

Membrane Preparation. The anion-introduced PVAs, CPVA and S-PVA (25 $2 \mu \mathrm{M}$ in thickness) were prepared as described in previous works. ${ }^{5,78}$ Briefly, for C-PVA preparation, PVA (MW: $1.46 \times 10^{3} \sim 8.5 \times 10^{4}$, Aldrich Chemical Company, Milwaukee, WI) was dissolved in $6 \mathrm{wt} \% \mathrm{NaOH}$ aq. solution and then stirred intensely overnight to introduce alkoxide groups into the PVA chain. Monochloroacetic acid was added to the PVA solution with a concentration ranging from 2 to $12 \mathrm{wt} \%$. These solutions were stirred followed by neutralization with $\mathrm{NaOH}$ solution, consecutively washing with ethanol and acetone. For S-PVA preparation, different amounts of sulfuric acid were added into the $10 \mathrm{wt} \%$ of aqueous PVA solution and stirred violently at $30^{\circ} \mathrm{C}$ for 24 hrs. These solutions were neutralized by $\mathrm{Na}_{2} \mathrm{CO}_{3}$ followed by washing with ethanol and acetone, consecutively. Concentrations of sulfuric acid used in this experiment were one to five times greater than those of $\mathrm{OH}$ groups in PVA. In the cases of carboxymethylation and sulfonation, salts produced by neutralization were eliminated with a semi-permeable cellulose acetate membrane. The substitution ratio of $\mathrm{C}$ - and S-PVA samples were determined by acid-base titration, sulfur analysis, and the elemental analysis (EA 1110, Carlo Erba) as described in our previous studies. C- and S-PVA casting solutions were prepared by dissolving C- and S-PVA powder of $25 \%$ substitution efficiency into hot water $\left(90^{\circ} \mathrm{C}\right)$ with a given concentration of a glutaraldehyde. Then the solutions were cast onto glass plate before gelation, and dried at $60^{\circ} \mathrm{C}$ in a convection oven over $24 \mathrm{hrs}$. The heat treatment of these membranes was done for $30 \mathrm{~min}$ in a $\mathrm{N}_{2}$ atmosphere at $120^{\circ} \mathrm{C}$. The sheet type Cuprophane (250-PM, $25 \mu \mathrm{M}$ in thickness, Enka, Germany) was used as a negative control, because Cuprophane represents the hydrophilic polymers for hemodialyzer production; over $70 \%$ of all hemodialyzers are still prepared from cellulosics under the trade name Cuprophane.

Critical Surface Tension., ${ }^{9}$ The contact angle of liquidsolid interfaces (water, methylene iodide, and the graft) was measured with the use of an Erma contact angle meter G-1. Critical surface tensions of all samples were calculated by the Owens Equation. ${ }^{11}$

Degree of Swelling. ${ }^{12}$ The completely dried samples of known weight were dipped into the petri dish filled with deionized water whose temperature was maintained at $37^{\circ} \mathrm{C}$ in an incubator for $4 \mathrm{hrs}$. The degree of swelling, $Q_{w}(\%)$, of these samples were calculated with following equation, $Q_{w}(\%)=\left[\left(W_{2}-W_{1}\right) / W_{1}\right] \times 100$, where $W_{1}$ and $W_{2}$ are the weight of dried and swollen samples, respectively.

Zeta Potential. Surface potentials of samples were examined by $\zeta$-potential measurements, which were performed using an ELS-8000 electrophoretic light-scattering spectrophotometer equipped with a plated sample cell (Otsuka Electronics, Tokyo, Japan). Samples were cut squarely in 3 $\times 4 \mathrm{~cm}$ size plates. The measurements were carried out at $25^{\circ} \mathrm{C}$ in $10 \mathrm{mM} \mathrm{NaCl}$ phosphate buffer solution ( $\mathrm{pH} \sim 7.2$, ionic strength 0.08 ) with polystyrene latex monitor particle (particle diameter $\sim 520 \mathrm{~nm}$ ), coated with hydroxypropylcellulose (HPC, $\left.M_{w}=300,000\right)$.

Plasma Collection. Whole blood from healthy donors were collected into a 400-mL blood bag (Green Cross Co. Ltd., Korea) containing $56 \mathrm{~mL}$ of Citrate Phosphate Dextrose Adenine anticoagulant solution (CPDA-1), and centrifuged for $30 \mathrm{~min}$ at $3,000 \mathrm{~g}$. The plasma was pooled and stored at $-70^{\circ} \mathrm{C}$.

Incubation. Membrane samples were cut into strips of 1 $\times 4 \mathrm{~cm}$, and washed with phosphate buffered saline (PBS, $\mathrm{pH}$ 7.4) three times for $15 \mathrm{~min}$. The washed membrane strips were cut into pieces of $1 \times 0.5 \mathrm{~cm}$ and incubated with $750 \mu \mathrm{L}$ of plasma in an Eppendorf tube for 15, 30, 90, and $240 \mathrm{~min}$ at room temperature with continuous shaking.

Elution of Plasma Protein. The incubated membrane samples were washed three times with PBS ( $\mathrm{pH} 7.4)$, and transferred to Eppendorf tubes containing $2 \%(\mathrm{w} / \mathrm{v})$ sodium dodecyl sulfate (SDS) and $14.4 \mathrm{mM} \beta$-mercaptoethanol solution at $90^{\circ} \mathrm{C}$ for $10 \mathrm{~min} \cdot{ }^{13}$ The tubes were vortexed for $10 \mathrm{~min}$ and sonicated at $28 \mathrm{KHz}$ using an ultrasonic generator (Ulsso Hi-Tech Ltd., Seoul, Korea) for 5 min. The efficiency of the desorption treatment was checked by staining the samples with coomassie brilliant blue (CBB) following usual procedures. ${ }^{14}$ The eluent was transferred to a $15 \mathrm{~mL}$ tube, and SDS dissolved in the eluent was removed by precipitation of the eluted proteins with methanol-chloroform-water (4:1:3) for protein analyses. ${ }^{15}$ The precipitates were air-dried, frozen, and stored at $-70^{\circ} \mathrm{C}$.

SDS-Polyacrylamide Gel Electrophoresis (SDS-PAGE). The precipitates were dissolved in a loading buffer containing $60 \mathrm{mM}$ Tris- $\mathrm{HCl}, \mathrm{pH}$ 6.8, 25\% glycerol, 2\% SDS, $14.4 \mathrm{mM}$, and $0.1 \%$ bromophenol blue. In order to denature the proteins, the solutions were re-mixed with $5 \times$ loading buffer and boiled at $95^{\circ} \mathrm{C}$ for $7 \mathrm{~min}$. They were then subjected to discontinuous SDS-PAGE on Criterion ${ }^{\mathrm{TM}}$ Precast Tris-HCl 4 20\% gel (Bio-Rad Laboratories, Hercules, CA) with a constant power of $200 \mathrm{~V}-\mathrm{h}$ for $55 \mathrm{~min}$. SDS-PAGE gels were stained with $\mathrm{CBB}$, and the bands were quantified using a Bioimage scanner (Milipore).

Western Blotting. The precipitates were quantified using reducing agent compatible and detergent compatible (RC DC) reagent (Bio-Rad Laboratories, Hercules, CA). Approximately $10 \mu \mathrm{g}$ of precipitates of each membrane samples and $5 \mu \mathrm{L}$ of loading buffer were loaded onto $12 \%$ SDS-polyacrylamide gel according to the method of Laemmli ${ }^{16}$ using Bio-Rad apparatus (Bio-Rad Laboratories, Hercules, CA) with a constant power of $120 \mathrm{~V}-\mathrm{h}$ for $90 \mathrm{~min}$. The electrophoresised proteins were transferred onto nitrocellulose membranes, which were then cut out and incubated with appropriate rabbit or mouse antiserum against the following proteins: C3 (Dako); albumin, apolipoprotein E (Apo E), 
transferrine, and $\alpha$-1 antitrypsin (Fitzgerald); $\operatorname{IgG}$ (Serotech); fibrinogen and prothrombin (Biomeda); $\alpha-2$ macroglobulin (Axell); and hemopexin (Nordic). An horseradish peroxidaselabelled (HRP) reagent conjugate and enhanced chemiluminescence (ECL) kit (Amersham Pharmacia Inc., Centennial Avenue, $\mathrm{PO}$ ) were used for revelation.

Two-dimensional Polyacrylamide Gel Electrophoresis (2D-PAGE). Protein samples for 2D-PAGE ( $25 \mu \mathrm{g}$ each) were mixed with rehydration buffer [6 $\mathrm{M}$ urea, $2 \mathrm{M}$ thiourea, $4 \%(\mathrm{w} / \mathrm{v})$ dithiothreitol (DTT), and 2\% (v/v) immobilized $\mathrm{pH}$ gradient (IPG) buffer] to a total volume of $400 \mu \mathrm{L}$, and applied to IPG strips, $\mathrm{pH} 3-10 \mathrm{~L}(180 \times 3 \times 0.5 \mathrm{~mm})$. After rehydration for $22 \mathrm{hrs,} \mathrm{first-dimensional} \mathrm{isoelectric} \mathrm{focusing}$ (IEF) was performed on precast immobilized dry strips in a Multiphor II IEF system (Amersham Pharmacia Biotech) for a total of $9 \times 10^{4} \mathrm{~V}$-h, with the initial voltage of $100 \mathrm{~V}$ and the final voltage of $8,000 \mathrm{~V}$. For IEF separation, the gel strip was equilibrated in a test tube containing $6 \mathrm{M}$ urea, $2 \%$ (w/v) SDS, $50 \%$ (v/v) glycerol, $5 \mathrm{mM}$ tributyl phosphine (TBP), and $2.5 \%$ acrylamide for 20 min with gentle shaking. The second-dimensional separation was performed on 9-16\% linear gradient SDS polyacrylamide gels. The gels $(200 \times 250 \times 1.0 \mathrm{~mm})$ were placed into an ISO-DALT system (Hoefer Scientific Instruments, San Francisco, CA), and were run overnight at $10-15 \mathrm{~mA}$ per gel until the bromophenol blue marker dye in the bottom of the gel disappeared. They were then fixed for $1 \mathrm{hr}$ in a mixture of 30 and $10 \%$ methanol and acetic acid, respectively, rinsed briefly with water, and stained with SYPRO ${ }^{\circledR}$ Ruby for $16 \mathrm{hrs}$. After destaining with a mixture of 10 and $7 \%$ methanol and acetic acid, respectively, for $4 \mathrm{hrs}$, the gels were stained with colloidal CBB G250 for $24 \mathrm{hrs}$, and scanned at $63.5 \mu \mathrm{m} /$ pixel optical resolution using a GS-800 calibrated densitometer (Bio-Rad Laboratories, Hercules, CA). 2D-PAGE gel spots were analyzed by Melanie III software (Swiss Institute for Bioinformatics, Geneva, Switzerland).

\section{Results and Discussion}

Figure 1 shows the CBB-stained gels of proteins eluted from Cuprophane, PVA, C-PVA, S-PVA, and samples following a $30 \mathrm{~min}$ exposure to CPDA-treated human plasma. The protein patterns differed both qualitatively and quantitatively, although common bands were found at 67, 54, 50, 28 and $26 \mathrm{kDa}$. Some of the plasma proteins were preferentially adsorbed, eg., 50 and $26 \mathrm{kDa}$ for Cuprophane and $54 \mathrm{kDa}$ for S-PVA. The common bands were scanned, and optical densities of the bands recorded. Total optical densities of the bands are shown in Figure 2. The amount of total bound proteins decreased in the order of Cuprophane, PVA, C-PVA, and S-PVA. Total protein adsorption to artificial surface can be explained by the physicochemical properties of surfaces, such as hydrophilicity and surface charges. These properties of samples were listed in Table I. Cupro-

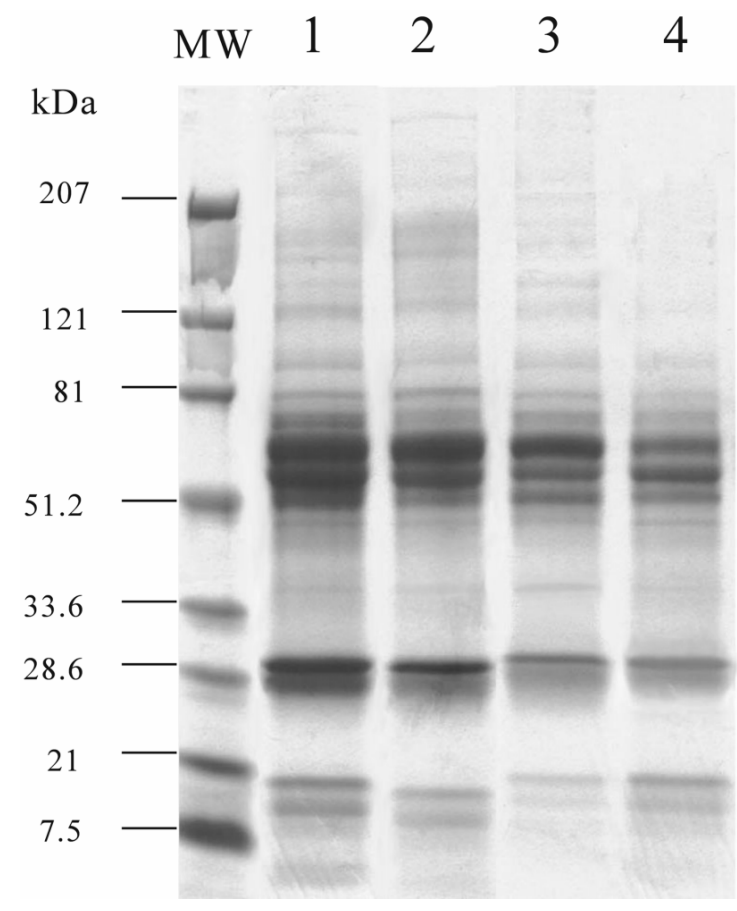

Figure 1. SDS-PAGE gel showing the adsorption of plasma proteins onto Cuprophane (lane 1); PVA (lane2); C-PVA (lane 3); S-PVA (lane 4) after incubation with plasma for $30 \mathrm{~min}$.

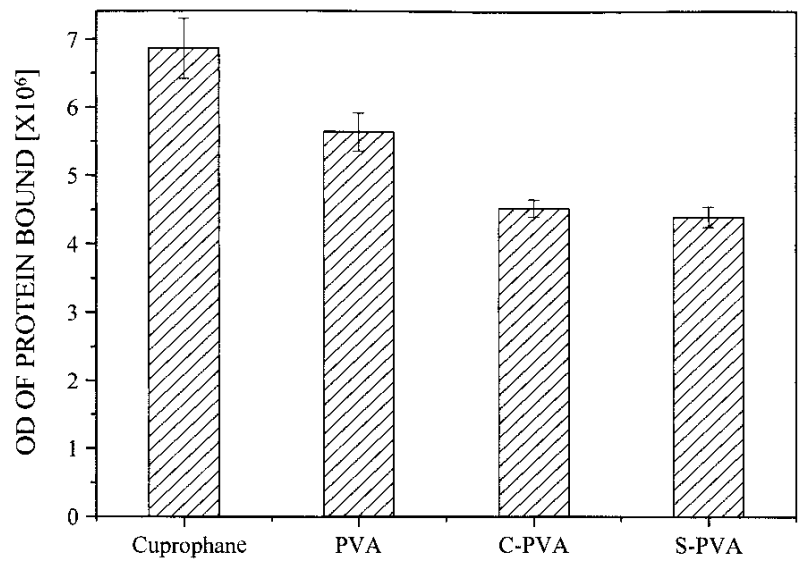

Figure 2. Binding of total plasma proteins onto Cuprophane, PVA, C-PVA, S-PVA samples.

phane has a hydrophilic structure, whose critical surface tension is $\sim 41 \mathrm{dyn} / \mathrm{cm}$, which enables it adsorb lesser amount of plasma proteins on its surface than on those of synthetic materials such as polycarbonate and polyacrylonitrile membranes. ${ }^{17}$ Total amount of plasma proteins bound to the PVA surface was 0.82 -fold of that of Cuprophane, though critical surface tension of PVA was found to be less than that of Cuprophane. This may be attributed to the differences in the 
swelling behavior of Cuprophane and PVA. Cuprophane, as regenerated cellulose, has hydrophilic characteristics due to hydroxyl groups in its backbone chain, however, its unlimited molecular weight as well as high crystallinity makes it swell hardly. ${ }^{17}$ PVA, on the other hand, exhibits an excellent swelling behavior, and this can be controlled by heat-treatment and cross-linking degree, as demonstrated in our previous studies. ${ }^{5,8}$ Due to this hydrophilic property, numerous investigations have been undertaken on the blood compatibility of PVA. ${ }^{18,19}$ Ikada et al. reported that lesser amounts of bovine albumin and fibrinogen adsorbed to PVA than to cellulose. ${ }^{18}$ In addition, the amount of proteins bound to PVA decreased with an increase in the surface tension of PVA. Duncan et al. also reported that PVA, interestingly, exerts higher protein adsorption capacity when its hydrophobicity is greater. ${ }^{19}$ In the cases of the modified PVAs, the amount of total bound protein decreased even further, i.e., 0.80- and 0.77-fold for C-PVA and S-PVA, respectively, compared to PVA, though critical surface tensions of $\mathrm{C}$ - and S-PVAs were found to be decreased compared to PVA. Previous studies revealed that both critical surface tensions and swelling ratios of C- and S-PVA decreased due to self-esterification and carbonization reaction, respectively. ${ }^{5,8}$ This implies that the enhanced protein repelling ability of modified C- and SPVA cannot be explained by hydrophilic properties of samples, exclusively. Aside from the wettability of the surfaces of materials, surface charge also plays an important role in the adsorption of the protein to the samples. In accord with a number of reports, introducing the charge groups to materials may provide changes in the protein uptake from plasma due to electrostatic interactions. ${ }^{20-22}$ As listed in Table I, all samples generated negative zeta potentials, and the amount of potentials increased in the order of PVA $\leq$ Cuprophane $<$ C-PVA $<$ S-PVA. Basically, non-heat treated PVA gives very small zeta potentials, because it has a diffuse surface due to the absent of crystallinites. However, both Cuprophane, which is not soluble in water under any condition, and heattreated PVA with a high degree of crystallinity may have the zeta potentials between those of solid and diffuse surfaces. ${ }^{18}$ As expected, C- and S-PVA exhibited negatively large zeta potentials, because the chains have an electric charge by themselves.

Kiremitci et al. revealed that the uptake of proteins to the charged surface is not only related to the type and density of the surface charge, but also to the structural properties of the proteins. $^{22}$ This finding suggests that some of the proteins reveal their own specific affinity to charged surfaces. Therefore, in order to investigate the patterns of adsorption to the charged surface revealed by individual proteins, individual bands were identified by immunoblotting. Because most of the proteins bound to all samples were present on the PVA membrane (Figure 1), the immunoblots were run with eluates from the PVA sample. Eleven identical eluates from the PVA membrane exposed to human plasma for $30 \mathrm{~min}$ were run on SDS-PAGE and blotted onto nitrocellulose. Figure 3 shows the eleven immunoblots of the eluates from PVA membrane. Briefly, fibrinogen showed three major bands, presumed to be $\alpha, \beta$, and $\gamma$ chains at 68,56 and $48 \mathrm{kDa}$, respectively. Albumin showed a strong band at $66 \mathrm{kDa}$, whereas the response of IgG to PVA membrane was weak at $55 \mathrm{kDa}$. The strong bands for $\alpha-1$ antitrypsin, prothrombin, and transferrin were visible at 53,75 and $77 \mathrm{kDa}$, respectively. Response of Apo E was also found at $34 \mathrm{kDa}$, and complement C3 showed strong bands at $\sim 118$ and $73 \mathrm{kDa}$. Figure 4 illustrates plasma protein bound to PVA sample with respect to exposure time. Vroman et al. showed that fibrinogen initially adsorbed from plasma onto artificial surfaces is displaced within a few minutes by two other plasma proteins, high molecular weight kininogen (HMWK) and factor XII; ${ }^{23}$ this transient binding of fibrinogen is known as the "Vroman effect". Slack et al. also suggested that other plasma proteins such as albumin and hemoglobin might displace fibrinogen adsorption. ${ }^{24}$ However, the "Vroman effect" did not occur with the samples tested in this study. This conclusion is based on the following two observations. In Figure 4, the amount of band 9, identified as fibrinogen $\beta$ chain, was constant during the first $30 \mathrm{~min}$, and increased throughout the exposure time. Secondly, band 3, identified as HMWK, showed similar adsorption trends to fibrinogen $\beta$ chain; however, the extent of band 3 was much lower than that of fibrinogen $\beta$ chain throughout the test period. In addition, the content of albumin did not increase with adsorption time. For a more precise interpretation, two-dimensional electrophoresis, which separate proteins by molecular weight as well as charge, are highly recommended, because onedimensional SDS-PAGE gel may not display proteins with very similar molecular weights. Figure 5 shows 2D-PAGE of proteins eluted from PVA, C-PVA, and S-PVA samples with 15 min exposure time. It represents the separated major proteins identified by reference maps. ${ }^{25}$ Albumin was the

Table I. Physicochemical Properties of Samples $(n=3)$

\begin{tabular}{lccc}
\hline \multicolumn{1}{c}{ Sample } & Critical Surface Tension $(\mathrm{dyn} / \mathrm{cm})$ & Degree of Swelling $(\%)$ & Zeta Potential $(\zeta, \mathrm{mV})$ \\
\hline Cuprophane & 41.3 & 4 & -17.67 \\
PVA & 35.7 & 36 & -17.45 \\
C-PVA & 32.4 & 32 & -25.08 \\
S-PVA & 35.1 & 23 & -41.73 \\
\hline
\end{tabular}




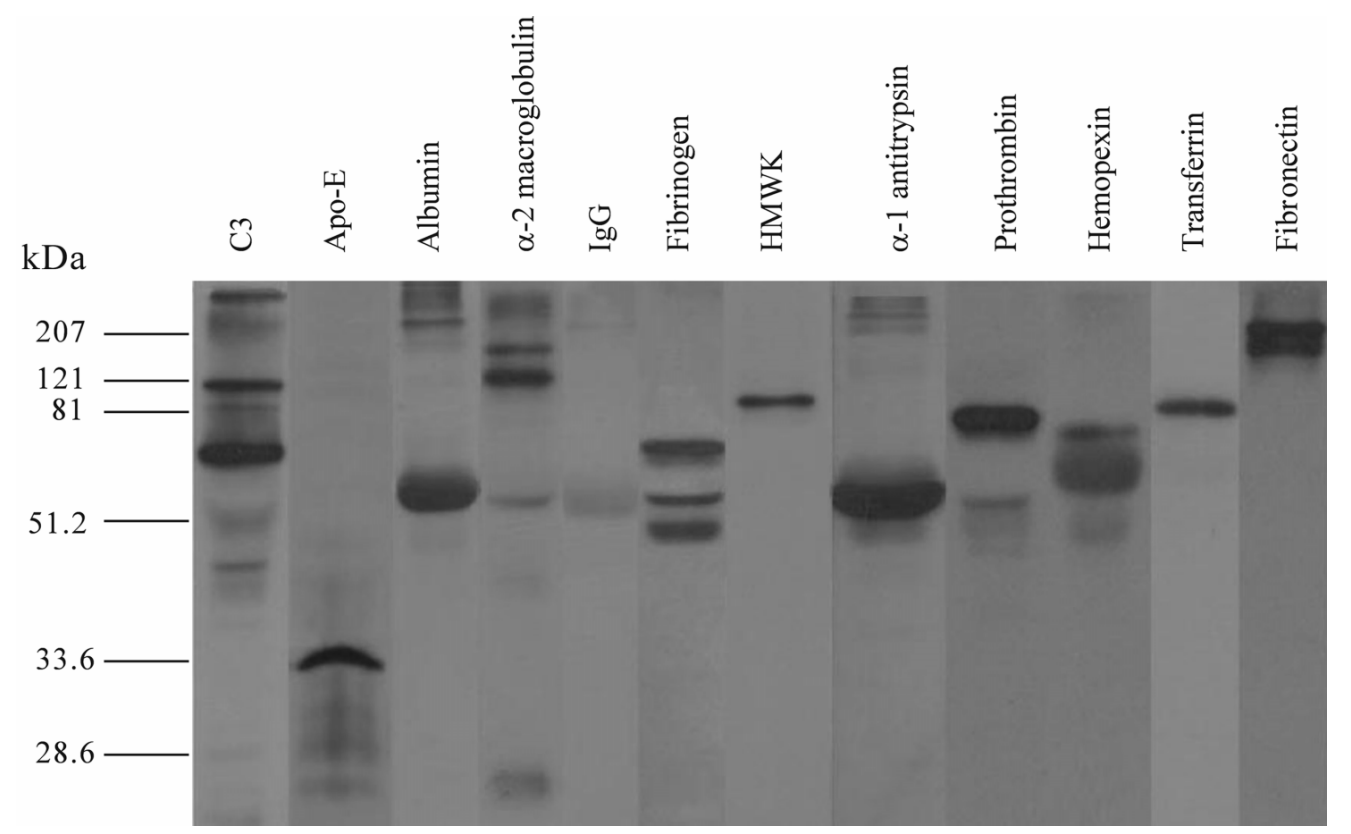

Figure 3. Immunoblots of proteins eluted from PVA following a 30 min exposure to human plasma.

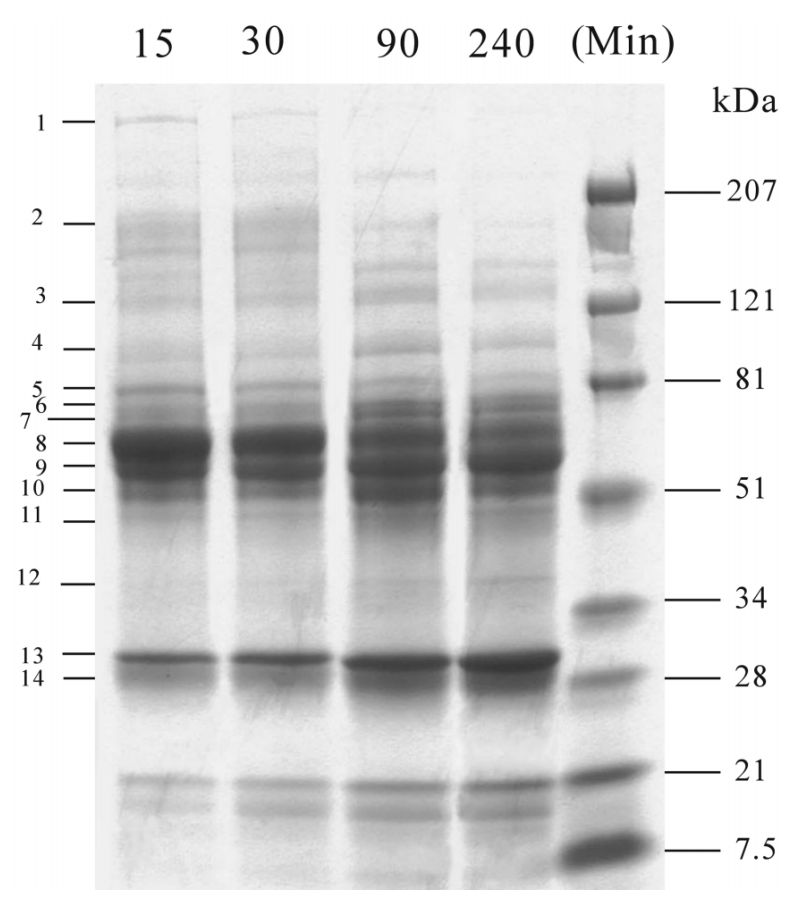

Figure 4. SDS-PAGE gel showing the kinetics of plasma protein adsorption onto PVA. The incubation time is indicated above the lane. Proteins eluted from PVA biomaterial. MW, molecular weight makers. 1. High molecular weight proteins; 2 . $\alpha$-2 macroglobulin; 3. HMWK; 4. Plasminogen; 5. Transferrin; 6. Prothrombin; 7. Fibrinogen $\alpha$ chain; 8. Albumin; 9. Fibrinogen $\beta$ chain, $\alpha-1$ antitrypsin; 10 . Fibrinogen $\gamma$ chain, $\operatorname{IgG}$ heavy chain; 11. Haptoglobulin $\beta$ chain; 12. Apo E; 13. IgG light chain; 14. ApoA-1. most abundant protein among all samples, and the gels dominated by its expanded spot. The preferential adsorption patterns of proteins to the samples were shown Figure 6. The extent of fibrinogen uptake of samples increased in the order of PVA, C-PVA, and S-PVA. Cooper and Brash proposed that $-\mathrm{SO}_{3}$ groups have strong binding affinity toward fibrinogen; that is, the amount of adsorbed fibrinogen on the surfaces of the sulfonated materials increased, although the sulfonate groups were negatively charged. ${ }^{26,27}$ On the other hand, C-PVA and S-PVA exhibited slightly increased ApoA1 adsorptions compared to PVA. Breemharr et al. reported that ApoA-1 and fibrinogen appeared to compete for the surfaces of the materials, such that binding of one protein inhibited the binding of the other. ${ }^{28}$ However, the results of Figure 6 were not in good agreement with those of Breemharrs proposal, probably because the strong affinity of fibrinogen for negatively charged sulfonate groups overcame the competition characteristics of ApoA-1.

Our previous anticoagulation study revealed that the adhesion and activation of platelets decreased in the order of PVA, C-PVA, and S-PVA. ${ }^{5}$ The proportion of adsorbed fibrinogen to S-PVA sample exceeded those for PVA and C-PVA (Figure 6). Adsorbed fibrinogen has been considered important for the adhesion of platelet. On the other hand, Harfenist et al. reported that platelets contain a receptor site specific for fibrinogen, which is active only when the platelets are activated. The correlation between platelets and proteins on the surface is still controversial. However, taking other proteins that may have influence on the platelet activation into consideration, S-PVA adsorbs the least amount of IgG, which is known as the promoter of platelet adhesion and activation. ${ }^{29}$ 


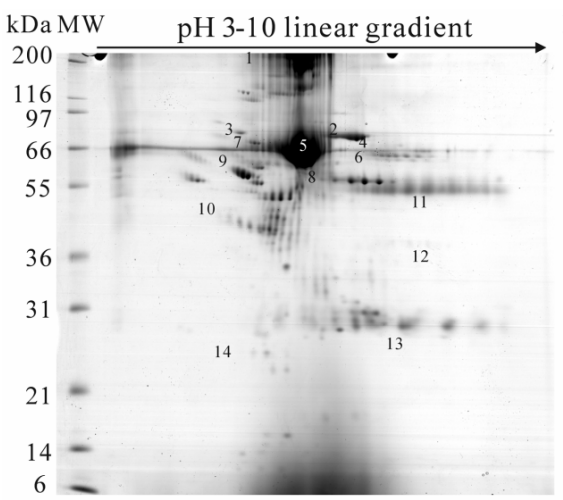

A

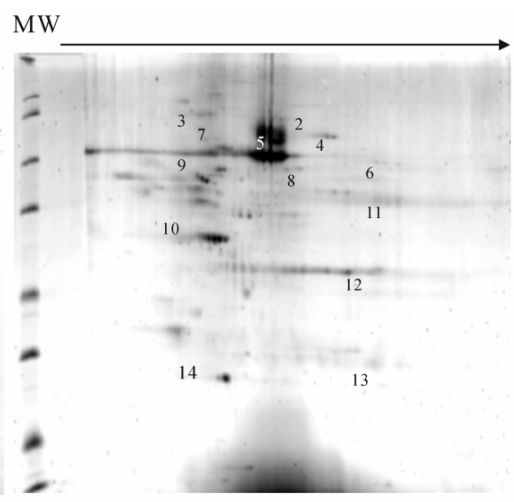

B

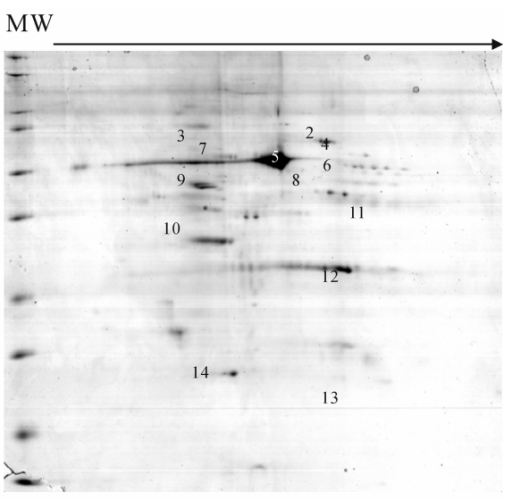

C

Figure 5. Two dimensional polyacrylamide gel electrophoresis of plasma proteins bound to PVA (A), C-PVA (B), S-PVA (c). The left lane shows the molecular weight marker: 1. $\alpha$-2 macroglobulin; 2. Transferrin; 3. Prothrombin; 4. C3; 5. Albumin; 6. Fibrinogen $\alpha$ chain; 7. Hemopexin; 8. Fibrinogen $\beta$ chain; 9. $\alpha$-1 antitrypsin; 10. Fibrinogen $\gamma$ chain; 11. IgG heavy chain; 12 . IgG heavy chain $\gamma, 13$. IgG light chain; 14. ApoA-1.

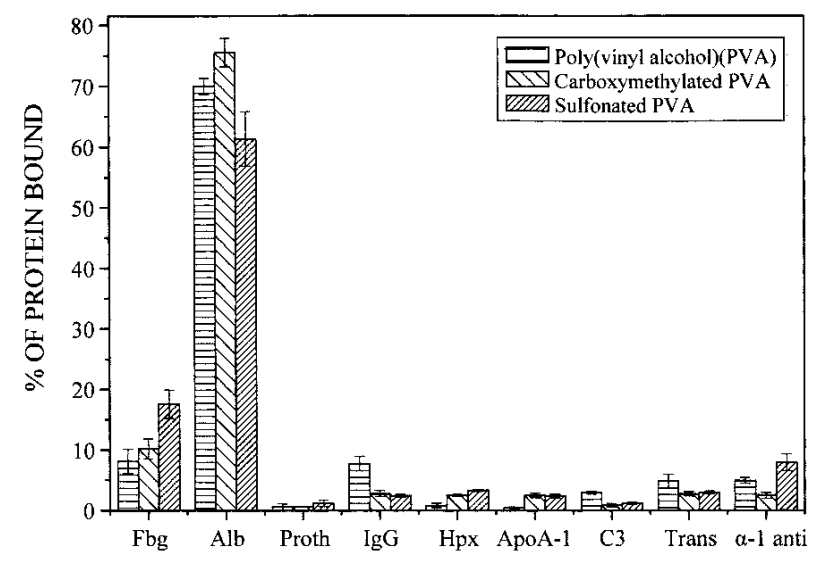

Figure 6. Binding of major plasma proteins onto poly(vinyl alcohol)(PVA), carboxymethylated PVA, sulfonated PVA samples.

Uchino et al. found that adsorbed IgG promotes the aggregation of platelets, and this aggregation was induced by the reaction of an antibody with a specific antigen on the normal platelet membrane through stimulus-response coupling. ${ }^{30}$ In addition, albumin was the most abundant protein bound to S-PVA, although the percentage of albumin to S-PVA was slightly lower than those for PVA and C-PVA. Consequently, the improved anticoagulation activities of S-PVA may be attributed to the adsorption characteristics of individual protein to the surface of material.

Other proteins of importance are the complement proteins. Since the realization of a complement activation capacity by artificial surfaces upon contact with blood, a common belief has evolved that nucleophilic surface groups such as hydroxyl and amine react with and eventually bind to the internal thioester in $\mathrm{C} 3 .{ }^{31}$ The drawback of the regenerated cellulose is the presence of hydroxyl groups that trigger the comple- ment activation and transient leukopenia. As a polyhydroxyl compound, PVA membrane may provide possible analogies with those of cellulose. The existence of $\mathrm{C} 3$ on the surface of samples was revealed through western blotting (Figure 3 ). The bands at 230, 118, and $73 \mathrm{kDa}$ corresponded to the intact phase $\mathrm{C} 3$, and $\alpha$ - and $\beta$ - chains of $\mathrm{C} 3 \mathrm{~b}$, respectively. ${ }^{3}$ The lower band at $43 \mathrm{kDa}$ could be attributed to an intermediate product involved in the conversion of $\mathrm{C} 3 \mathrm{~b}$ into $\mathrm{C} 3 \mathrm{bi}{ }^{4}$ However, detection of these bands on 1D SDS-PAGE gels was difficult. Furthermore, $\beta$-chain of $\mathrm{C} 3 \mathrm{~b}$ could only be detected by 2D-PAGE gels. Although C-PVA and S-PVA showed lower affinity to C3 than PVA on 2D-PAGE gels, this was of little significance. The complement activation on the surfaces of materials occurs through far more complicated stages; the other complement factors including $\mathrm{Bb}, \mathrm{C} 5 \mathrm{~b}$, and C5b-9 involved complement activation against the surfaces of materials. ${ }^{32}$ Therefore, in addition to the results of $\mathrm{C} 3$, continuation of the study on the behavior of total complements on the samples through an alternative pathway is necessary.

In conclusion, the amount of total bound proteins decreased in the order of Cuprophane, PVA, C-PVA, and S-PVA. This can be attributed to the fact that surface characteristics of the samples, such as surface tension, degree of swelling and surface charge, may affect protein adsorption profiles to materials. However, it is evident that the decrease in total protein adsorption of C- and S-PVA compared to PVA and Cuprophane is largely dependant upon their increased negative potentials due to anionic substitution. The adsorption patterns of individual proteins to the samples were found to be different. S-PVA sample showed the highest adsorption for fibrinogen, and lowest for IgG. This may be attributed that binding affinity of $-\mathrm{SO}_{3} \mathrm{H}$ groups on samples to the individual proteins is different. 
Acknowledgements. This work has been supported by Korea Food and Drug Administration; Grant, KFDA-02091TIS-041.

\section{References}

(1) J. D. Andrade, Principles of Protein Adsorption in Surface and Interfacial Aspects of Biomedical Polymers, Plenum Publishing, New York, 1985, pp 1-80.

(2) T. A. Horbett, Protein Adsorption on Biomaterials in Biomaterials: Interfacial Phenomena and Applications, S. L. Cooper and N. A. Peppas, Eds., ACS Advances in Chemistry Series, ACS, Washington DC, 1982, Vol.199, pp 233-244.

(3) S. R. Mulzer and J. L. Brash, J. Biomed. Mater. Res., 23, 1483 (1989).

(4) S. Parzer, P. Balcke, and C. Mannhalter, J. Biomed. Mater. Res., 27, 455 (1993).

(5) H. J. Chun, J. J. Kim, and K. Y. Kim, Polymer J., 22, 347 (1990).

(6) A. Finch, Poly(vinyl alcohol)-Development, John Wiley \& Sons Ltd., New York, 1992.

(7) H. J. Chun, J. J. Kim, S. H. Lee, K. Y. Kim, and U. Y. Kim, Polymer J., 22, 477 (1990).

(8) S. Y. Nam, H. J. Chun, and Y. M. Lee, J. Appl. Polym. Sci., 72, 241 (1999).

(9) G. Khang, M. K. Choi, J. M. Rhee, S. J. Lee, H. B. Lee, Y. Iwasaki, N. Nakabayashi, and K. Ishihara, Korea Polym. J., 9, 107 (2001).

(10) K. C. Hong, J. H. Kim, and J. Y. Bae, Korea Polym. J., 9, 253 (2001).

(11) D. Owens, J. Appl. Polym. Sci., 13, 1711 (1969).

(12) S. K. Min, J. H. Kim, and D. J. Chung, Korea Polym. J., 9, 143 (2001).

(13) M. Berger, B. Broxup, and M.V. Sefton, J. Mater. Sci., 5, 622 (1994).

(14) M. C. Tanzi, M. Muttoni, R. Fumero, S. Scuri, and G. Cairo,
Polymers in Medicine III, C. Migliaresi, Ed., Elsevier Science Publishers B.V., Amsterdam, 1987, pp 99-110.

(15) D. Wessel and U. I. Flügge, Anal. Biochem., 138, 141 (1984).

(16) U. K. Laemmli, Nature, 227, 680 (1990).

(17) P. M. Galletti, C. K. Colton, and M. J. Lysaght, The Biomedical Engineering Handbook, J. D. Bronzino, Ed., CRC Press Inc., 1995, pp 1898-1922.

(18) Y. Ikada, H. Iwata, F. Horii, T. Matsunaga, M. Tanigushi, and M. Suzuki, J. Biomed. Mater. Res., 15, 697 (1981).

(19) A. C. Duncan, M. V. Sefton, and J. L. Brash, Biomaterials, 18, 1585 (1997).

(20) J. H. Lee, H. W. Kim, P. K. Pak, S. S. Kim, and H. B. Lee, Korea Polym. J., 2, 32 (1994).

(21) D. K. Han, K. D. Park, G. H. Ryu, U. Y. Kim, B. G. Min, and Y. H. Kim, J. Biomed. Mater. Res., 30, 23 (1996).

(22) M. Kiremitci, E. Gok, and S. Ates, J. Biomater. Sci. Polym. Ed., 6, 425 (1994).

(23) L. Vroman, Bull. N.Y. Acad. Med., 64, 352 (1988).

(24) S. M. Slack, J. L. Bohnert, and T. A. Horbett, Ann. N. Y. Acad. Sci., 516, 223 (1987).

(25) A.Gessner, A. Lieske, B. R. Paulke, and R. H. Müller, Eur. J. Pharm. Biopharm., 54, 165 (2002).

(26) T. G. Grasel and S. L. Cooper, J. Biomed. Mater. Res., 23, 311 (1989).

(27) J. P. Santerre, N. H. Vanderkaup, and J. L. Brash, J. Biomed. Mater. Res., 26, 39 (1992).

(28) W. Breemhaar, E. Brinkman, D. J. Elleus, T. Bengeling, and A. Bantjes, Biomaterials, 5, 269 (1984).

(29) E. J. Harfenist, M. A. Packham, and J. F. Mustard, Blood, 64, 1163 (1984).

(30) T. Sugiyama, M. Okuma, F. Ushikubi, S. Seusaki, K. Kanaji, and H. Uchino, Blood, 69, 1712 (1987).

(31) J. Wettero, A. Askeudal, T. Bengtsson, and P. Tengvall, Biomaterials, 23, 981 (2002).

(32) I. Roitt, J. Brostoff, and D. Male, Immunology, $5^{\text {th }}$ Edition, Mosby International Ltd., London, 1998, pp 43-59. 